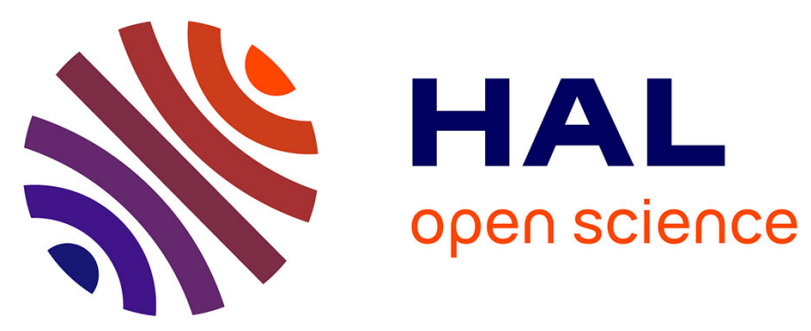

\title{
Occurrence and distribution of glycerol dialkanol diethers and glycerol dialkyl glycerol tetraethers in a peat core from SW Tanzania
}

Sarah Coffinet, Arnaud Huguet, David Williamson, Laurent Bergonzini, Christelle Anquetil, Amos Majule, Sylvie Derenne

\section{To cite this version:}

Sarah Coffinet, Arnaud Huguet, David Williamson, Laurent Bergonzini, Christelle Anquetil, et al.. Occurrence and distribution of glycerol dialkanol diethers and glycerol dialkyl glycerol tetraethers in a peat core from SW Tanzania. Organic Geochemistry, 2015, 83-84, pp.170-177. 10.1016/j.orggeochem.2015.03.013 . hal-01141971

\section{HAL Id: hal-01141971 \\ https://hal.sorbonne-universite.fr/hal-01141971}

Submitted on 14 Apr 2015

HAL is a multi-disciplinary open access archive for the deposit and dissemination of scientific research documents, whether they are published or not. The documents may come from teaching and research institutions in France or abroad, or from public or private research centers.
L'archive ouverte pluridisciplinaire HAL, est destinée au dépôt et à la diffusion de documents scientifiques de niveau recherche, publiés ou non, émanant des établissements d'enseignement et de recherche français ou étrangers, des laboratoires publics ou privés. 


\title{
Occurrence and distribution of glycerol dialkanol diethers and glycerol dialkyl glycerol tetraethers in a peat core from SW Tanzania
}

\author{
Sarah Coffinet $^{\mathrm{a}, \mathrm{b}}$, Arnaud Huguet ${ }^{\mathrm{a}, \mathrm{b} *}$, David Williamson ${ }^{\mathrm{c}}$, Laurent Bergonzini ${ }^{\mathrm{d}}$, \\ ChristelleAnquetil $^{\mathrm{a}, \mathrm{b}}$, Amos Majule ${ }^{\mathrm{e}}$, Sylvie Derenne ${ }^{\mathrm{a}, \mathrm{b}}$ \\ ${ }^{\mathrm{a}}$ CNRS, UMR 7619, METIS, F-75005, Paris, France \\ ${ }^{\mathrm{b}}$ Sorbonne Universités, UPMC Univ. Paris 06, UMR 7619, METIS, F-75005, Paris, France \\ ${ }^{\mathrm{c}}$ Institut de Recherche pour le Développement, UMR 7159, LOCEAN, Centre IRD France \\ Nord, F-93143, Bondy cedex, France \\ ${ }^{d}$ CNRS-UPS UMR 8148, GEOPS, F-91405 Orsay, France \\ ${ }^{\mathrm{e}}$ Institute of Resource Assessment,University of Dar Es Salaam, PO Box 35097, Dar Es \\ Salaam, Tanzania
}

\section{ABSTRACT}

Isoprenoid and branched glycerol dialkanol diethers (iso GDDs and br GDDs) have recently been detected in various environments, including sediment, soil and peat deposits. Their structures strongly resemble those of glycerol dialkyl glycerol tetraethers (GDGTs). Nevertheless, the origin of GDDs and their link to GDGTs remain unclear. Here we examined the concentration and distribution of iso GDDs and br GDDs, together with those of iso GDGTs and br GDGTs along a $4 \mathrm{~m}$ peat core from Tanzania. Whereas br GDDs have only been detected to date in their core lipid (CL) form, we report here, for the first time, br GDDs in both CL and intact polar lipid (IPL) forms, suggesting a biosynthetic origin for br GDDs. Concentration of br GDGTs and br GDDs on one hand, and of iso GDGTs and iso GDDs on the other hand, were observed to significantly co-vary $\left(\mathrm{R}^{2} 0.49-0.58 ; p<0.05\right)$, both for the $\mathrm{CL}$ and IPL fractions. Moreover, the fractional abundance of each GDD correlated significantly with that of its GDGT analogue $\left(\mathrm{R}^{2} 0.33-0.97 ; p<0.05\right)$. Taken together, the data show that GDDs and GDGTs are closely related and likely take part in common

"Corresponding author. Tel : + 33-144-275-172; fax: +33-144-275-150.

E-mail address: arnaud.huguet@upmc.fr (A. Huguet). 
metabolic pathways, although the hypothesis of GDDs being degradation products of GDGTs cannot be excluded.

\section{Keywords}

GDGTs; GDDs; peat core; Tanzania.

\section{Introduction}

Glycerol dialkyl glycerol tetraethers (GDGTs) were first described as components of membranes from Archaea (Langworthy, 1977) and later from unknown Bacteria (Sinninghe Damsté et al., 2000). Archaeal-derived GDGTs feature isoprenoid chains bound to glycerol through ether linkages (Fig. 1) while bacterially-derived GDGTs are characterised by branched alkyl chains instead of biphytanes. The terms isoprenoid (iso GDGTs) and branched (br GDGTs) are used to distinguish the two types of GDGTs. Both iso GDGTs and br GDGTs occur ubiquitously in aquatic and terrestrial environments (Schouten et al., 2013). They have been the subject of growing interest over the last decade, notably because their structures were shown to vary depending on environmental parameters (Schouten et al., 2002; Weijers et al., 2007). Iso GDGTs can be used as temperature proxies in the aquatic environment via the TEX $_{86}$ index (Schouten et al., 2002), whereas the MBT/CBT indices (methylation index of branched tetraethers/cyclisation ratio of branched tetraethers), based on the distribution of br GDGTs in soils and peats, allow reconstruction of mean annual air temperature and $\mathrm{pH}$ (Weijers et al., 2007). Since their introduction, GDGT-derived proxies have been extensively used to reconstruct paleoenvironmental parameters (Schouten et al., 2013).

Recently, a range of new glycerol ether lipids have been detected (Liu et al., 2012a), including glycerol dialkanol diethers (GDDs) which resemble GDGTs, in that the alkyl chains are attached to a glycerol at one end and to hydroxyl groups at the other end (Fig. 1). Like 
GDGTs, both GDDs with isoprenoid alkyl chains (iso GDDs; e.g. Liu et al., 2012b) and with branched alkyl chains (br GDDs; Yang et al., 2014) have been detected, suggesting a dual archaeal and bacterial origin for these lipids. They were found in sediment (Knappy and Keely, 2011; Liu et al., 2012a, b; Becker et al., 2013; Meador et al., 2014), soil (Yang et al., 2014) and peat (Liu et al., 2012b). The iso GDDs were also found in pure archaeal cultures (Liu et al., 2012a, b; Meador et al., 2014). Yet, neither their source, function or association with GDGTs have been clearly determined. Two hypotheses were proposed (Liu et al., 2012a; Meador et al., 2014; Yang et al., 2014): GDDs could be (i) degradation products of GDGTs or (ii) biosynthetic compounds, either as structural membrane compounds or as GDGT intermediates. Meador et al. (2014) characterised a series of iso GDD IPLs with a glycosidic head group in estuarine and hot spring sediments as well as in a pure archaeal culture (Nitrosopumilus maritimus). This suggests that at least part of the iso GDD pool is of biosynthetic origin. Indeed, in living cells, membrane lipids are bound to a polar head group (sugar and/or phosphate units; Nishihara and Koga, 1987). In contrast, the majority of the lipids found in natural environments have lost this head group upon cell death or lysis (White et al., 1979; Harvey et al., 1986; Logemann et al., 2011) and are detected as core lipids (structures in Fig. 1).

In order to investigate the presence and the origin of GDDs in terrestrial environments, we analysed iso and br GDGT and GDD distributions - either as core lipids (CLs) or derived from intact polar lipids (IPLs) - along a $4 \mathrm{~m}$ peat core from Tanzania, where GDGTs and GDDs were expected to be abundant. Indeed, the organic carbon $\left(\mathrm{C}_{\text {org }}\right)$ content is high in peat, as a result of low biodegradation activity (Laggoun Défarge et al., 2008). In addition, studies have shown that anaerobic peat bogs are enriched in br GDGTs, either due to an increase in source microorganisms or preservation (Weijers et al., 2006; Huguet et al., 2010). The objectives of this work were to (i) compare the variation in GDGT and GDD abundance and 
distribution with depth and (ii) test for the presence of GDD IPLs in the core. To the best of our knowledge, the detection of br GDDs in the IPL form has not been reported.

\section{Material and methods}

\subsection{Site and sampling}

The swamp of Kyambangunguru is located at $663 \mathrm{~m}$ above sea level (a.s.1.) near the Rungwe Mountain $\left(9^{\circ} 21.842 \mathrm{~S} 033^{\circ} 47.684 \mathrm{E}\right)$ in the southwest of Tanzania (Fig. 2). The region is located in the humid equatorial zone of Africa, with alternation of a hot humid season (November to June) and a dry cold season (June to October), as described previously (Coffinet et al., 2014). The swamp, at the centre of a volcanic crater, is a former maar lake, which was transformed gradually into an ombrotrophic peatbog. It is closed (i.e. without outlet) and drains a small steep catchment of ca. $0.2 \mathrm{~km}^{2}$. Its water level fluctuates from a high level, ca. $70-80 \mathrm{~cm}$, at the end of the rainy season (May-June) to a relatively low level after the end of the dry one (December; Delalande et al., 2008). A 4 m core was collected with a Wright corer in the centre of the Kyambangunguru swamp in November 2012. It represents ca. 4,000 $\mathrm{yr}$ of peat deposition, according to comparison between the bottom tephra layer and tephra layers dated independently for cores collected in nearby lakes (Lake Malawi and Lake Masoko; Garcin et al., 2007). The core was sampled in the field at $1 \mathrm{~cm}$ resolution. Samples were kept at $-20^{\circ} \mathrm{C}$ and then freeze dried. GDGTs and GDDs in 24 samples selected every 15 $\mathrm{cm}$ from the core were analyzed. 


\subsection{Elemental analysis}

The $\mathrm{C}_{\text {org }}$ content of the samples was determined from elemental analysis performed at the Service Central d'Analyse du CNRS, Villeurbanne, France.

\subsection{Sample preparation}

Each sample (ca. 1 g dry wt.) was extracted following a modified Bligh-Dyer procedure, as described by Huguet et al. (2013). The extract was separated into three fractions after elution from a $2 \mathrm{~cm}$ diameter column of silica (activated overnight at $130{ }^{\circ} \mathrm{C}$ ). Briefly, the first fraction, containing the apolar lipids, was eluted with $40 \mathrm{ml}$ dichloromethane (DCM); the second, containing the CLs, was eluted with $48 \mathrm{ml} \mathrm{DCM:Me} 2 \mathrm{CO}(2: 1, \mathrm{v}: \mathrm{v})$, followed by $30 \mathrm{ml}$ DCM:Me ${ }_{2} \mathrm{CO}(1: 1, \mathrm{v}: \mathrm{v})$ and the last fraction, containing the IPLs, was eluted with 40 ml DCM:MeOH (1:1, v:v) followed by $30 \mathrm{ml} \mathrm{MeOH}$. This fraction was separated into 2 aliquots. About $80 \%$ of the fraction was subjected to acid methanolysis in $1 \mathrm{M} \mathrm{HCl} / \mathrm{MeOH}$ for $24 \mathrm{~h}$ at $100^{\circ} \mathrm{C}$ to cleave off the polar head groups of the GDGT IPLs and release the corresponding CLs. The mixture was then diluted in $\mathrm{MeOH}$ and rotary evaporated under near vacuum to neutralise the hydrolysed aliquot which was then dried under $\mathrm{N}_{2}$, dissolved in $1 \mathrm{ml}$ heptane and centrifuged using an Eppendorf Mini Spin centrifuger (1 min, $7000 \mathrm{rpm})$. Its analysis was performed using high performance liquid chromatography - atmospheric pressure chemical ionisation mass spectrometry (HPLC-APCI-MS).The second aliquot of the fraction (ca. 20\%) was analysed directly using HPLC-MS to determine the carryover of CLs into the IPL fraction, which amounted to $<5 \%$ of the CLs detected after acid methanolysis of the third fraction. The second fraction was directly rotary evaporated after fractionation over the silica column, dried under $\mathrm{N}_{2}$, dissolved in $1 \mathrm{ml}$ heptane and centrifuged using an Eppendorf Mini Spin centrifuger (1 min, 7000 rpm) before HPLC-APCI-MS analysis. 


\subsection{GDGT and GDD analysis}

HPLC-APCI-MS was performed with a Shimadzu LCMS-2020. Separation was achieved with a Prevail Cyano column $(2.1 \mathrm{~mm}$ x $150 \mathrm{~mm}, 3 \mu \mathrm{m}$; Alltech, Deerfield, IL, USA) at $30^{\circ} \mathrm{C}$, using a mixture of $\mathrm{A}$ and $\mathrm{B}$ (A,hexane and $\mathrm{B}$,isopropanol) at $0.2 \mathrm{ml} / \mathrm{min}$. Elution began at $99 \%$ A/1\% B for 5 min followed by a linear gradient to $98 \%$ A/2\% B in 45 min. A second linear gradient led to a mixture of $90 \%$ A/10 \% B in 10 min, maintained for 10 min and returned to the initial conditions $(99 \% \mathrm{~A} / 1 \% \mathrm{~B})$ in $14 \mathrm{~min}$, maintained for $10 \mathrm{~min}$. Injection volume was $10 \mu$ l. Single ion monitoring $(\mathrm{SIM})$ of the $[\mathrm{M}+\mathrm{H}]^{+}$ions was used to detect the GDGTs and GDDs (Fig. 1). Semi-quantification of the GDGTs was performed by comparing the integrated signal of the respective compound with the signal of a $\mathrm{C}_{46}$ synthesised internal standard, as described by Huguet et al. (2013).

Fractional abundances of the major br GDGTs and br GDDs were calculated as follows:

$$
f(i)=i /(V I I a+V I I I a+I X a)
$$

Where $i$ is the concentration of the corresponding br GDGT or br GDD and roman numerals refer to the structures in Fig. 1.

In the same way, fractional abundances of each iso GDD and iso GDGT were determined according to the equation:

$$
f(i)=i /(I+I I+I I I+I V+V I)
$$

The ratio of iso vs. br GDGTs, $\mathrm{R}_{\mathrm{i} / \mathrm{b}}$, was calculated by dividing the summed iso GDGT concentration by that of br GDGTs, as proposed by Xie et al. (2012). Similarly, the ratio $\mathrm{R}_{\mathrm{i} / \mathrm{b}}$ was determined for the GDDs.

Analytical uncertainty was determined by injecting 5 samples in triplicate. Error on fractional abundances was $<1 \%$ for GDGTs and $<4 \%$ for GDDs. 


\subsection{Statistical analysis}

Potential correlation between the concentration of br GDGT and br GDD CLs was tested by calculating the correlation coefficient. In the same way potential correlations between the concentration of br GDGT and br GDD IPLs, as well as iso GDGT and iso GDD concentration in the CL and IPL fractions were also tested. The correlations were considered significant when the $p$ value was $<0.05$. Similarly the $\mathrm{R}_{\mathrm{i} / \mathrm{b}}$ for GDGTs and GDDs, as well as the fractional abundance of each individual GDGT/GDD pair [e.g. $f$ (iso GDGT I) and $f($ iso GDD I), $f$ (br GDGT IXa) and $f($ br GDD IXa), etc.] were compared by calculating the correlation coefficients. Whenever each of the 2 elements was normally distributed, the Pearson correlation coefficient was calculated (8 among the 20 comparisons); otherwise, we determined the Spearman correlation coefficient instead (12 among the 20 correlations). Outliers (in black in the different graphs) were defined by plotting the corresponding residuals vs. leverage graph for each correlation. Whenever a data point was outside the Cook's distance, it was considered an outlier. Data analysis was performed using the $\mathrm{R}$ software ( $\mathrm{R}$ Core Team, 2013).

\section{Results and discussion}

\subsection{Variation in GDGT and GDD concentration with depth}

Br GDGTs and iso GDGTs were detected in every sample, both in the CL and IPL fractions. In the CL fraction, total br GDGT concentration varied between 61.4 and 633.0 $\mu \mathrm{g} / \mathrm{g} \mathrm{C}_{\text {org, }}$ and total iso GDGT concentration between 18.3 and $235.5 \mu \mathrm{g} / \mathrm{g} \mathrm{C}_{\text {org }}$ (Fig. 3a, b and Supplementary Table 1). Br GDGT CL concentration (2.4-354.5 $\mu \mathrm{g} / \mathrm{g}$ dry wt. peat) in the Kyambangunguru swamp is in the lower end range of those in a $1 \mathrm{~m}$ core from a Swiss peatland (20-1700 $\mu \mathrm{g} / \mathrm{g}$ dry wt. peat; Weijers et al., 2011) and comparable with those in a 50 
cm German peat core (140-370 $\mu \mathrm{g} / \mathrm{g}$ dry wt. peat; Liu et al., 2010). Similarly, iso GDGT CL concentration in Kyambangunguru $(0.7-131.6 \mu \mathrm{g} / \mathrm{g}$ dry wt. peat) is generally lower than in the above Swiss peat core $(10-700 \mu \mathrm{g} / \mathrm{g}$ dry wt. peat; Weijers et al., 2011) but higher than in a German peat core (2-17 $\mu \mathrm{g} / \mathrm{g}$ dry wt. peat; Liu et al., 2010). Both br and iso GDGT CL concentrations in the Kyambangunguru swamp are also much higher than in surficial soils from the Mt. Rungwe area (1.1-8.3 $\mu \mathrm{g} / \mathrm{g} \mathrm{C}_{\text {org }}$ and $0.05-1.5 \mu \mathrm{g} / \mathrm{g} \mathrm{C}_{\text {org }}$ for br GDGTs and iso GDGTs respectively; Coffinet et al., 2014). This is consistent with observations that br GDGTs and iso GDGTs are especially abundant in peat deposits, suggesting that the anaerobic and acidic conditions there are favourable for the growth of GDGT source microorganisms and/or for GDGT preservation (Pancost et al., 2000; Weijers et al., 2006; Huguet et al., 2010).

In addition to GDGTs, br GDDs and iso GDDs were also detected in the CL and IPL fractions of all samples (Figs. 3a, b, d, e).This is the first indication of br GDD IPLs in natural samples. GDD CL concentration ranged between 0.5 and $26.2 \mu \mathrm{g} / \mathrm{g} \mathrm{C}_{\mathrm{org}}$, while GDD IPL concentration was between 0.2 and $1.3 \mu \mathrm{g} / \mathrm{g} \mathrm{C}_{\text {org }}$ (Figs. 3a, b, d, e and Supplementary Table 1). The proportion of GDDs relative to the total lipid pool (GDDs + GDGTs) ranged between 1 and $6 \%$ for br GDDs and iso GDDs in the CL fraction, and between 1 and $8 \%$ for br GDDs and iso GDDs in the IPL fraction, which is in the same range as in previous studies $(3.5-17 \%$ for iso GDD CLs in marine sediments, Liu et al., 2012a; 2-15\% for br GDD CLs and 6-16\% for iso GDD CLs in soils, Yang et al, 2014; 7-10\% for iso GDD CLs and 3-4\% for iso GDD IPLs in estuarine sediments, Meador et al., 2014).

Depth profiles of iso GDGT and iso GDD concentration were comparable (Figs. 3b, 3e) and correlated significantly for both lipid pools $\left(\mathrm{R}^{2} 0.56\right.$ and 0.58 for the CL and IPL fractions, respectively; $p<0.05 ; \mathrm{n}=24$ ), as observed by Meador et al. (2014) for estuarine sediments. Br GDGT and br GDD concentrations along the core were also found to correlate 
significantly $(p<0.05)$ in both the CL $\left(\mathrm{R}^{2} 0.42\right.$; Fig. 3a) and IPL $\left(\mathrm{R}^{2} 0.47\right.$; Fig. 3d) pools. In addition, the proportion of iso GDGTs vs. br GDGTs; the $\mathrm{R}_{\mathrm{i} / \mathrm{b}}$ ratio (Xie et al., 2012) covaried significantly $(p<0.05)$ with $\mathrm{R}_{\mathrm{i} / \mathrm{b}}$ for GDDs, both for the CL $\left(\mathrm{R}^{2} 0.49\right.$; Fig. 3c) and IPL fractions ( $R^{2}$ 0.58; Fig. 3f). A similar trend was observed by Yang et al. (2014) for $R_{i / b}$ of GDD and GDGT CLs in Chinese soils and in a loess-paleosol sequence. Taken together, the consistent correlations between GDDs and GDGTs argue for a close relationship between the two types of compounds, either in their source, preservation or degradation.

In the CL fraction, the concentrations of br and iso GDGTs on the one hand, and br and iso GDDs on the other hand, showed comparable variation with depth $\left(\mathrm{R}^{2} 0.90\right.$ and 0.76 for GDGTs and GDDs, respectively; $p<0.05$; Supplementary Fig. 1). Similarly, Weijers et al. (2009) observed a co-variation between iso GDGT and br GDGT CL concentration in a peat core from Sweden. The co-variation may be due to favourable environmental growth conditions in peat - such as anaerobic conditions (Pancost et al., 2000; Weijers et al., 2006) shared by both archaea- and bacteria-producing GDGTs. Alternatively and/or complementarily, this might indicate that the branched and isoprenoid compounds (either GDDs or GDGTs) have similar turnover in peat.

The concentration of br and iso GDGT and GDD CLs in Kyambangunguru peat core increased from the surface to $150 \mathrm{~cm}$, where they reached a maximum and then decreased to a minimum at the bottom of the core $(405 \mathrm{~cm}$; Figs. $3 \mathrm{a}, \mathrm{b})$. The depth profiles are similar to those observed for br and iso GDGTs by Weijers et al. $(2006,2011)$ for three peat cores from Switzerland, Sweden and the UK. This may be due to (i) the high accumulation rate of peat and (ii) the good preservation of organic matter (OM), and especially GDGTs (and GDDs), at these depths, as suggested by Weijers et al. (2006). It should be noted that we are here comparing a tropical peatland with 3 temperate ones. Additional peat cores from contrasting climatic environments need to be studied to confirm the generality of the trend. 
GDGTs and GDDs in the IPL form were abundant all along the core, especially between ca. 1 and $2 \mathrm{~m}$ depth for br GDGTs (Fig. 3d, e). This suggests the presence of GDGTproducing microorganisms all along the core. However, Xie et al. (2013) found the half life of bacterial IPLs to be $100-1000 \mathrm{yr}$ at $1 \mathrm{~m}$ depth in marine sediments, suggesting that fossil IPLs may be preserved in particular environments. Such a phenomenon could also occur in peatlands, due to the very low degradation rate of $\mathrm{OM}$ in peat. This has to be taken into account when interpreting the IPL data in such settings.

\subsection{Potential origin of GDDs}

\subsubsection{Relationship between GDGT and GDD distributions}

GDGT distributions were similar in the IPL and CL fractions for both iso GDGTs and br GDGTs (Supplementary Table 1), as observed in other peatlands (e.g. Huguet et al., 2010). Compound I was the most abundant iso GDGT in both CL and IPL fractions, with a fractional abundance between 55 and 84\% (Figs. 4a, 4e). Previous studies of peatlands support a dominant methanogenic origin for GDGT It, as both methanogenic Euryarchaeota and GDGT I are relatively abundant in this setting (e.g. Pancost et al., 2000; Kotsyurbenko et al., 2004; Weijers et al., 2009). In contrast, compound VI was only detected in 11 of the 24 samples, with a fractional abundance $<6.5 \%$ (cf. Supplementary Table 1). Fractional abundances of iso GDGTs II, III and IV were variable depending on the sample, but were systematically < $19.3 \%$ in both CL and IPL fractions (Fig. 4b-d, f-h). GDGT IXa was largely predominant among the br GDGTs, with a fractional abundance in the CL and IPL fractions between 65 and $91 \%$ for GDGT IXa (Figs. 5c, 5f). Fractional abundance of GDGT VIIIa was between 9 and $31 \%$, while that of GDGT VIIa was $\leq 4 \%$, whatever the lipid pool (Figs. 5a, b, d, e).

The relative distributions of the individual GDDs (either iso or br) were similar to those of the corresponding GDGTs, both in the CL and in the IPL fraction (Figs. 4 and 5). 
Fractional abundance of each iso GDD showed significant correlation $(p<0.05)$ with that of the corresponding iso GDGT $\left(\mathrm{R}^{2} 0.33\right.$ - 0.85) except for III in the CL fraction (Fig. 4c). The correlation between iso GDGT and iso GDD VI was significant only in the CL pool ( $\mathrm{R}^{2} 0.54$; $p<0.05$; data not shown) and was less robust as these compounds were only detected in 10 out of 24 samples. Like the isoprenoid compounds, a significant correlation $\left(\mathrm{R}^{2} 0.83-0.97 ; p\right.$ $<2.6 \times 10^{-6}$ ) was observed between the fractional abundance of non-cyclic br GDDs and that of the corresponding br GDGTs, whatever the lipid pool (Fig. 5). Cyclic br GDDs were tentatively assigned on the basis of their retention time and $[\mathrm{M}+\mathrm{H}]^{+}$values. Nevertheless, since the relative abundance was very low $(<1 \%)$ and no structural elucidation was performed, they were not considered further . Yang et al. (2014) observed similar correlations between fractional abundances of GDGT and GDD CLs in Chinese surface soil samples and terrestrial sediments. Our results confirm and extend their finding, as correlation between fractional abundances of both iso and br GDGTs and GDDs were found for the first time in the IPL pool. It strongly suggests that the two groups of compounds are closely related and share common metabolic and/or degradation pathways (Liu et al., 2012a; Meador et al., 2014; Yang et al., 2014), whatever their origin - archaeal or bacterial.

The correlations between individual br GDGT and br GDD relative abundances are close to the 1:1 line in both CL and IPL pools (Fig. 5), suggesting that the two types of compounds share a common source. It should be noted that the regression line for $f$ (br GDGT VIIIa) vs. $f$ (br GDD VIIIa) is slightly below the 1:1 line, indicating the relative accumulation of GDD VIIIa vs. GDGT VIIIa (Figs. 5b-e). An opposite trend was observed for GDGT IXa vs. GDD IXa (Figs. 5c-f). The correlations between individual iso IPL GDGT and iso IPL GDD relative abundances also fall near the 1:1 line (Fig. 4 e-h), indicating potential common sources for iso GDGTs and iso GDDs. In the CL pool, a selective enrichment in iso GDGT I vs. iso GDD I on the one hand (Fig. 4a) and in iso GDDs III and IV vs. iso GDGTs III and IV 
on the other hand (Fig. 4c and d) was observed for samples from the $74-180 \mathrm{~cm}$ horizon, which correspond to most of the statistically defined outliers. The selective accumulation of iso GDDs III vs. the corresponding GDGT analogue in this horizon may also explain the lack of correlation between $f($ GDGT III) and $f($ GDD III). Preliminary results of OM analysis (Coffinet et al., unpublished results) showed a clear shift from a lake to a peatland ecosystem in the 74-180 cm horizon. This may have led to changes in the composition of archaeal communities and also in the relative distribution of iso GDGTs and iso GDDs at these depths.

\subsubsection{Implications for origin of GDDs}

The occurrence of iso GDD IPLs in the Kyambangunguru peatland confirms the observation of Meador et al. (2014) in sediments and archaeal cultures and their proposition that these compounds are - at least partly - of biosynthetic origin, based on the hypothesis that IPLs are markers of living viable organisms. It is assumed that the first step in the degradation of GDGT IPLs would be loss of the polar head group bound to core GDGTs, via enzymatic hydrolysis (White et al., 1996; Meador et al., 2014) rather than the cleavage of the 2 glycerol ether bonds of GDGT IPLs to yield GDD IPLs. The detection, for the first time, of br GDDs in the IPL form argues that br GDDs could also have a biosynthetic origin based on the same rationale. Strong correlations were particularly found between each br GDD IPL and its CL counterpart ( $\mathrm{R}^{2}$ 0.31-0.93; $p<0.05$; Supplementary Fig. 2), implying that, like br GDGTs, br GDD CLs may derive from GDD IPLs. In addition, strong relationships between iso GDGT and GDD concentrations (Fig. 3b, 3e) on one hand and br GDGT and GDD concentrations (Figs. 3a, 3d) on the other hand, were observed along the peat core. As also discussed above, some iso and br GDDs were noticed to be selectively enriched relative to their GDGT counterparts between 74 and $180 \mathrm{~cm}$ depth (compounds III and IV; Fig. 4c-d) or over the whole core (compound VIIIa; Figs. 5b, 5e), suggesting a biosynthetic production of GDDs. 
Taken together, the observations support the idea that GDGTs and GDDs take part in similar or joint biosynthetic processes. However, the current hypotheses on the biosynthetic routes leading to the formation of GDGTs do not include GDD IPLs as biosynthetic intermediates of GDGTs. Indeed in the biosynthetic pathway of iso GDGTs, formation of the tetraether was described to occur via $\omega, \omega$ ' coupling of two diethers (Koga and Morii, 2007), and the biosynthetic pathway for br GDGTs proposed so far rather involves a dicarboxylic acid, isodiabolic acid (Sinninghe Damsté et al., 2011). Nevertheless, other unknown pathways for GDGT biosynthesis, in which GDDs would be involved, may exist.

Alternatively, GDDs could be both an intermediate and a degradation product of GDGTs. Takano et al. (2010) proposed a recycling pathway for the synthesis of iso GDGTs in extreme environments with very low energy input, such as deep sea sediments. This pathway involves the potential recycling of biphytane diols derived from the degradation of ancient GDGTs, which would be further linked to newly synthesized glycerol. Liu et al. (2012a) and Meador et al. (2014) proposed that iso GDDs may be involved in this pathway through glycerol addition or cleavage. Similar pathways are conceivable for br GDGTs. Further studies combining microbiology and geochemistry, notably for continental environments such as peatlands, are necessary to fully understand the role of GDDs in the environment. Nevertheless, the exact group(s) of bacteria biosynthesizing br GDGTs remain(s) unknown, even though some might belong to the phylum Acidobacteria (Weijers et al., 2009; Sinninghe Damsté et al., 2011). As long as the br GDGT source microorganisms are unknown, hypotheses on the origin and function of GDDs relative to GDGTs in bacterial membranes can only be speculative.

\section{Conclusions}


Br GDGTs, br GDDs, iso GDGTs and iso GDDs were detected in both the CL and IPL form along a 4 m peat core from SW Tanzania. This is the first report of br GDDs in the IPL form. Br GDD and iso GDD concentrations were found to co-vary significantly with br GDGT and iso GDGT abundances in both CL and IPL pools. Moreover, the relative abundance of each GDD was found to correlate significantly with its GDGT counterpart, the regression lines for GDGTs vs GDDs being approximately close to the 1:1 line for most of the compounds. Taken together, the results suggest a very close link between GDGTs and GDDs of either archaeal or bacterial origin. The detection of iso GDDs and br GDDs in the IPLderived fraction of the peat core, combined with the occurrence of iso GDD IPLs in sediments and in a pure archaeal culture (Meador et al., 2014), and the enrichment of some GDDs relative to their GDGT counterparts strongly argues in favor of a biosynthetic origin for at least part of the GDD pool, even though the hypothesis of GDDs being degradation products of GDGTs cannot be totally excluded. Additional studies are needed to fully understand the sources and fate of GDDs in natural environments.

\section{Acknowledgments}

We would like to thank the Tanzanians who helped us during the field campaign. We also thank the Université Pierre et Marie Curie for a PhD scholarship to S.C. and the EC2CO program (CNRS/INSU) for funding. We are grateful to B.D. Naafs and an anonymous reviewer for constructive comments.

Associate Editor - B. van Dongen

\section{References}

Becker, K.W., Lipp, J.S., Zhu, C., Liu, X.-L., Hinrichs, K.-U., 2013. An improved method for the analysis of archaeal and bacterial ether core lipids. Organic Geochemistry 61, 34-44. 
Coffinet, S., Huguet, A., Williamson, D., Fosse, C., Derenne, S., 2014. Potential of GDGTs as a temperature proxy along an altitudinal transect at Mount Rungwe (Tanzania). Organic Geochemistry 68, 82-89.

Delalande, M., Bergonzini, L., Massault, M., 2008. Mbaka lakes' isotopic $\left({ }^{18} \mathrm{O}\right.$ and $\left.{ }^{2} \mathrm{H}\right)$ and water balances: discussion on the used atmospheric moisture compositions. Isotopes in Environmental and Health Studies 44, 71-82.

Garcin, Y., Williamson, D., Bergonzini, L., Radakovitch, O., Vincens, A., Buchet, G., Guiot, J., Brewer, S., Mathé, P.-E., Majule, A., 2007. Solar and anthropogenic imprints on Lake Masoko (southern Tanzania) during the last 500 years. Journal of Paleolimnology 37, 475-490.

Harvey, H.R., Fallon, R.D., Patton, J.S., 1986. The effect of organic matter and oxygen on the degradation of bacterial membrane lipids in marine sediments. Geochimica et Cosmochimica Acta 50, 795-804.

Huguet, A., Fosse, C., Laggoun-Défarge, F., Toussaint, M.-L., Derenne, S., 2010. Occurrence and distribution of glycerol dialkyl glycerol tetraethers in a French peat bog. Organic Geochemistry 41, 559-572.

Huguet, A., Fosse, C., Laggoun-Défarge, F., Delarue, F., Derenne, S., 2013. Effects of a shortterm experimental microclimate warming on the abundance and distribution of branched GDGTs in a French peatland. Geochimica et Cosmochimica Acta 105, 294-315.

Knappy, C.S., Keely, B.J., 2011. Novel glycerol dialkanol triols in sediments: transformation products of glycerol dibiphytanyl glycerol tetraether lipids or biosynthetic intermediates? Chemical Communications 48, 841-843.

Koga, Y., Morii, H., 2007. Biosynthesis of ether-type polar lipids in Archaea and evolutionary considerations. Microbiology and Molecular Biology Reviews 71, 97-120.

Kotsyurbenko, O.R., Chin, K.-J., Glagolev, M.V., Stubner, S., Simankova, M.V., Nozhevnikova, A.N., Conrad, R., 2004. Acetoclastic and hydrogenotrophic methane production and methanogenic populations in an acidic West-Siberian peat bog. Environmental Microbiology 6, 1159-1173.

Laggoun-Défarge, F., Gilbert, D., Buttler, A., Epron, D., Francez, A.-J., Grasset, L., Mitchell, E.A.D., Guimbaud, C., Roy, J.-C., 2008. Effects of experimental warming on carbon sink function of a temperate pristine mire : the PEATWARM project, In: Farrell, C. and Feehan, J. (Eds.), After Wise Use - the Future of Peatlands. Proceedings of the 13th International Peat Congress, Ireland, Tullamore, 8-13, June 2008. IPS, Finland, pp. 599602.

Langworthy, T.A., 1977. Long-chain diglycerol tetraethers from Thermoplasma acidophilum. Biochimica et Biophysica Acta 487, 37-50.

Lipp, J.S., Hinrichs, K.-U., 2009. Structural diversity and fate of intact polar lipids in marine sediments. Geochimica et Cosmochimica Acta 73, 6816-6833. 
Liu, X.-L., Leider, A., Gillespie, A., Gröger, J., Versteegh, G.J.M., Hinrichs, K.-U., 2010.Identification of polar lipid precursors of the ubiquitous branched GDGT orphan lipids in a peat bog in Northern Germany. Organic Geochemistry 41, 653-660.

Liu, X.-L., Lipp, J.S., Schröder, J.M., Summons, R.E., Hinrichs, K.-U., 2012a. Isoprenoid glycerol dialkanol diethers: A series of novel archaeal lipids in marine sediments. Organic Geochemistry 43, 50-55.

Liu, X.-L., Summons, R.E., Hinrichs, K.-U., 2012b. Extending the known range of glycerol ether lipids in the environment: structural assignments based on tandem mass spectral fragmentation patterns. Rapid Communications in Mass Spectrometry 26, 2295-2302.

Logemann, J., Graue, J., Köster, J., Engelen, B., Rullkötter, J., Cypionka, H., 2011. A laboratory experiment of intact polar lipid degradation in sandy sediments. Biogeosciences 8, 2547-2560.

Meador, T.B., Zhu, C., Elling, F.J., Könneke, M., Hinrichs, K.-U., 2014. Identification of isoprenoid glycosidic glycerol dibiphytanol diethers and indications for their biosynthetic origin. Organic Geochemistry 69, 70-75.

Nishihara, M., Morii, H., Koga, Y., 1987. Structure determination of a quartet of novel tetraether lipids from Methanobacterium thermoautotrophicum. Journal of Biochemistry 101, 1007-1015.

Pancost, R.D., Geel, B. van, Baas, M., Damsté, J.S.S., 2000. $\delta^{13}$ C values and radiocarbon dates of microbial biomarkers as tracers for carbon recycling in peat deposits. Geology 28, 663-666.

R Core Team, 2013. R: A language and environment for statistical computing. R Foundation for Statistical Computing, Vienna, Austria (http://www.R-project.org/).

Schouten, S., Hopmans, E.C., Schefuß, E., Sinninghe Damsté, J.S., 2002. Distributional variations in marine crenarchaeotal membrane lipids: a new tool for reconstructing ancient sea water temperatures? Earth and Planetary Science Letters 204, 265-274.

Schouten, S., Middelburg, J.J., Hopmans, E.C., Sinninghe Damsté, J.S., 2010. Fossilization and degradation of intact polar lipids in deep subsurface sediments: a theoretical approach. Geochimica et Cosmochimica Acta 74, 3806-3814.

Schouten, S., Hopmans, E.C., Sinninghe Damsté, J.S., 2013. The organic geochemistry of glycerol dialkyl glycerol tetraether lipids: a review. Organic Geochemistry 54, 19-61.

Sinninghe Damsté, J.S., Hopmans, E.C., Pancost, R.D., Schouten, S., Geenevasen, J.A.J., 2000. Newly discovered non-isoprenoid dialkyl diglycerol tetraether lipids in sediments. Journal of the Chemical Society, Chemical Communications 23, 1683-1684.

Sinninghe Damsté, J.S., Rijpstra, W.I.C., Hopmans, E.C., Weijers, J.W.H., Foesel, B.U., Overmann, J., Dedysh, S.N., 2011. 13,16-Dimethyl octacosanedioic acid (iso-diabolic acid), a common membrane-spanning lipid of Acidobacteria subdivisions 1 and 3 . Applied Environmental Microbiology 77, 4147-4154. 
Takano, Y., Chikaraishi, Y., Ogawa, N.O., Nomaki, H., Morono, Y., Inagaki, F., Kitazato, H., Hinrichs, K.-U., Ohkouchi, N., 2010. Sedimentary membrane lipids recycled by deep-sea benthic archaea. Nature Geoscience 3, 858-861.

Weijers, J.W.H., Schouten, S., Hopmans, E.C., Geenevasen, J.A.J., David, O.R.P., Coleman, J.M., Pancost, R.D., Sinninghe Damsté, J.S., 2006. Membrane lipids of mesophilic anaerobic bacteria thriving in peats have typical archaeal traits. Environmental Microbiology 8, 648-657.

Weijers, J.W.H., Schouten, S., van den Donker, J.C., Hopmans, E.C., Sinninghe Damsté, J.S., 2007. Environmental controls on bacterial tetraether membrane lipid distribution in soils. Geochimica et Cosmochimica Acta 71, 703-713.

Weijers, J.W.H., Panoto, E., van Bleijswijk, J., Schouten, S., Rijpstra, W.I.C., Balk, M., Stams, A.J.M., Damsté, J.S.S., 2009. Constraints on the biological source(s) of the orphan branched tetraether membrane lipids. Geomicrobiology Journal 26, 402-414.

Weijers, J.W.H., Steinmann, P., Hopmans, E.C., Schouten, S., Sinninghe Damsté, J.S., 2011. Bacterial tetraether membrane lipids in peat and coal: testing the MBT-CBT temperature proxy for climate reconstruction. Organic Geochemistry 42, 477-486.

White, D.C., Davis, W.M., Nickels, J.S., King, J.D., Bobbie, R.J., 1979. Determination of the sedimentary microbial biomass by extractible lipid phosphate. Oecologia 40, 51-62.

White, G.F., Russell, N.J., Tidswell, E.C., 1996. Bacterial scission of ether bonds. Microbiological Reviews 60, 216-232.

Xie, S., Pancost, R.D., Chen, L., Evershed, R.P., Yang, H., Zhang, K., Huang, J., Xu, Y., 2012. Microbial lipid records of highly alkaline deposits and enhanced aridity associated with significant uplift of the Tibetan Plateau in the Late Miocene. Geology 40, 291-294.

Xie, S., Lipp, J.S., Wegener, G., Ferdelman, T.G., Hinrichs, K.-U., 2013. Turnover of microbial lipids in the deep biosphere and growth of benthic archaeal populations. Proceedings of the National Academy of Sciences USA 110, 6010-6014.

Yang, H., Pancost, R.D., Tang, C., Ding, W., Dang, X., Xie, S., 2014. Distributions of isoprenoid and branched glycerol dialkanol diethers in Chinese surface soils and a loesspaleosol sequence: implications for the degradation of tetraether lipids. Organic Geochemistry 66, 70-79. 


\section{Figure captions}

Fig. 1. Structures of isoprenoid and branched glycerol dialkyl glycerol tetraethers (GDGTs) and glycerol dialkanol diethers (GDDs).

Fig. 2. Location of sampling site (Kyambangunguru, Rungwe region, Tanzania).

Fig. 3. Depth profiles of GDD and GDGT concentration and of the ratio of isoprenoid to branched $\left(\mathrm{R}_{\mathrm{i} / \mathrm{b}}\right)$ ether lipids in CL (a-c) and IPL (d-f) fractions.

Fig. 4. Correlation between fractional abundances of individual iso GDGTs and iso GDDs. The dotted line represents the 1:1 line. The black points were considered as outliers and were not included in the correlations. Encircled data points correspond to samples from the $74 \mathrm{~cm}$ $180 \mathrm{~cm}$ depth horizon.

Fig. 5. Correlation between fractional abundances of individual br GDGTs and br GDDs. The dotted line represents the 1:1 line. The black points were considered as outliers and were not considered in the correlations. Error bars were added when they were larger than the symbols. 


\section{Figure}

$\mathrm{m} / \mathrm{z}$

iso GDGT I iso GDGT II iso GDGT III ${ }^{\text {Ho }}$ iso GDGT IV iso GDGT $\mathrm{V}$

iso GDGT VI $(+\mathrm{VI})$

br GDGT VIIa

br GDGT VIIb

br GDGT VIIc

br GDGT VIIIa

br GDGTVIIIb

br GDGTVIIIc

br GDGT IXa

br GDGT IXb
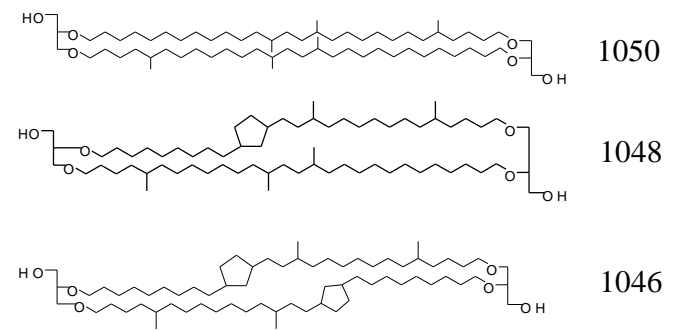

1036
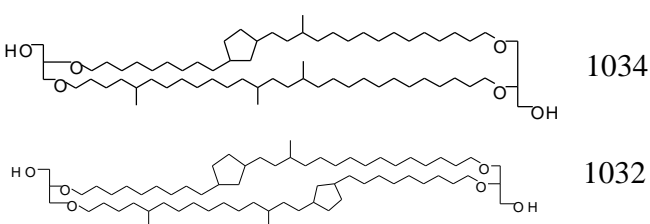

1022

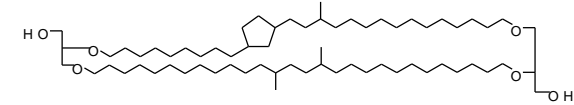

1020 br GDGT IXc iso GDD I

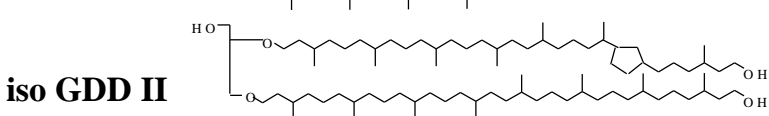

1244

iso GDD III ${ }^{\mathrm{H}}$

iso GDD IV ${ }^{\mathrm{H}}$

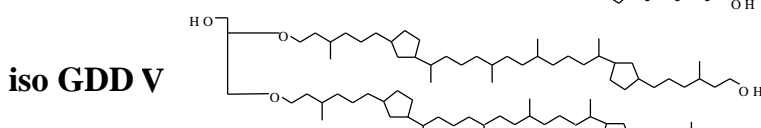

iso GDD VI

(+ VI')

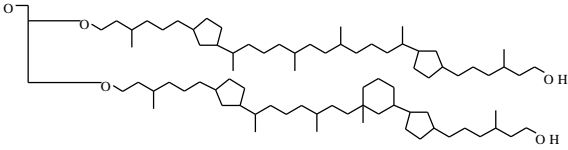

1236

br GDD $\mathrm{VIIa}{ }^{\mathrm{HO}}$

994

br GDD VIIb

992

br GDD VIIC ${ }^{\mathrm{O}}$

990

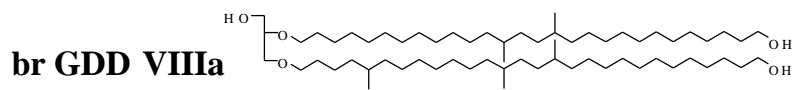

980

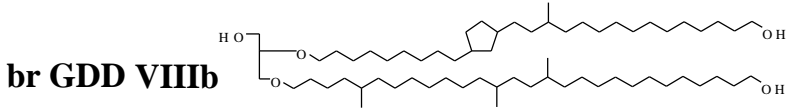

978

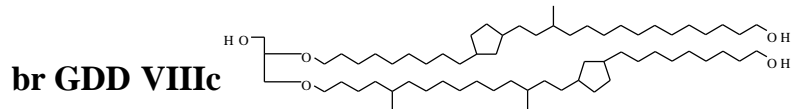

br GDD IXa ${ }^{\mathrm{O}}$

br GDD IXb ${ }^{\circ}$

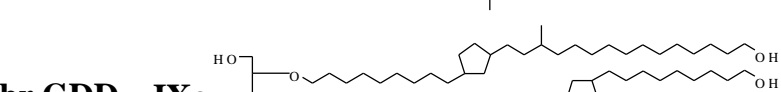
br GDD IXe
Figure 1. 


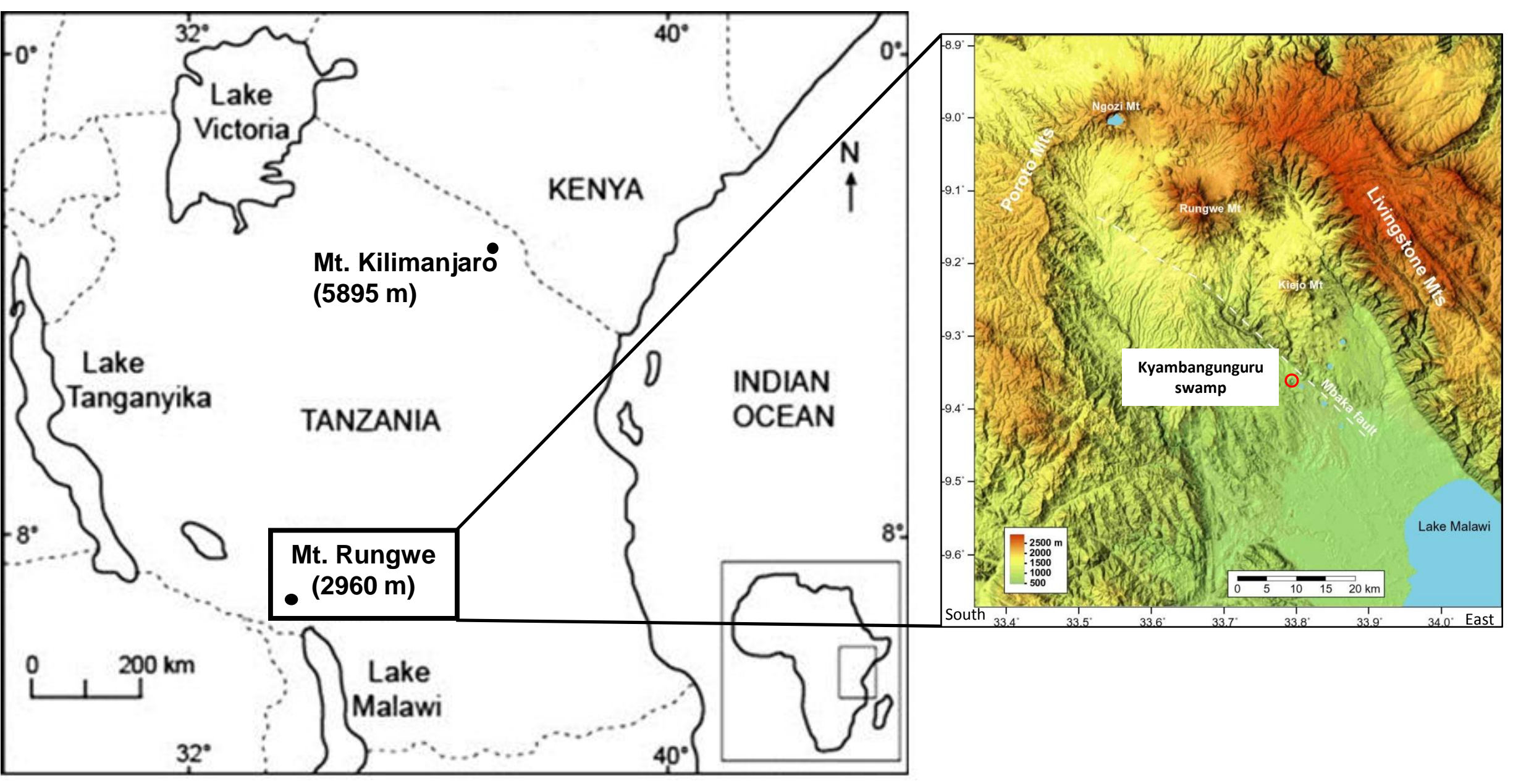

Figure 2. 

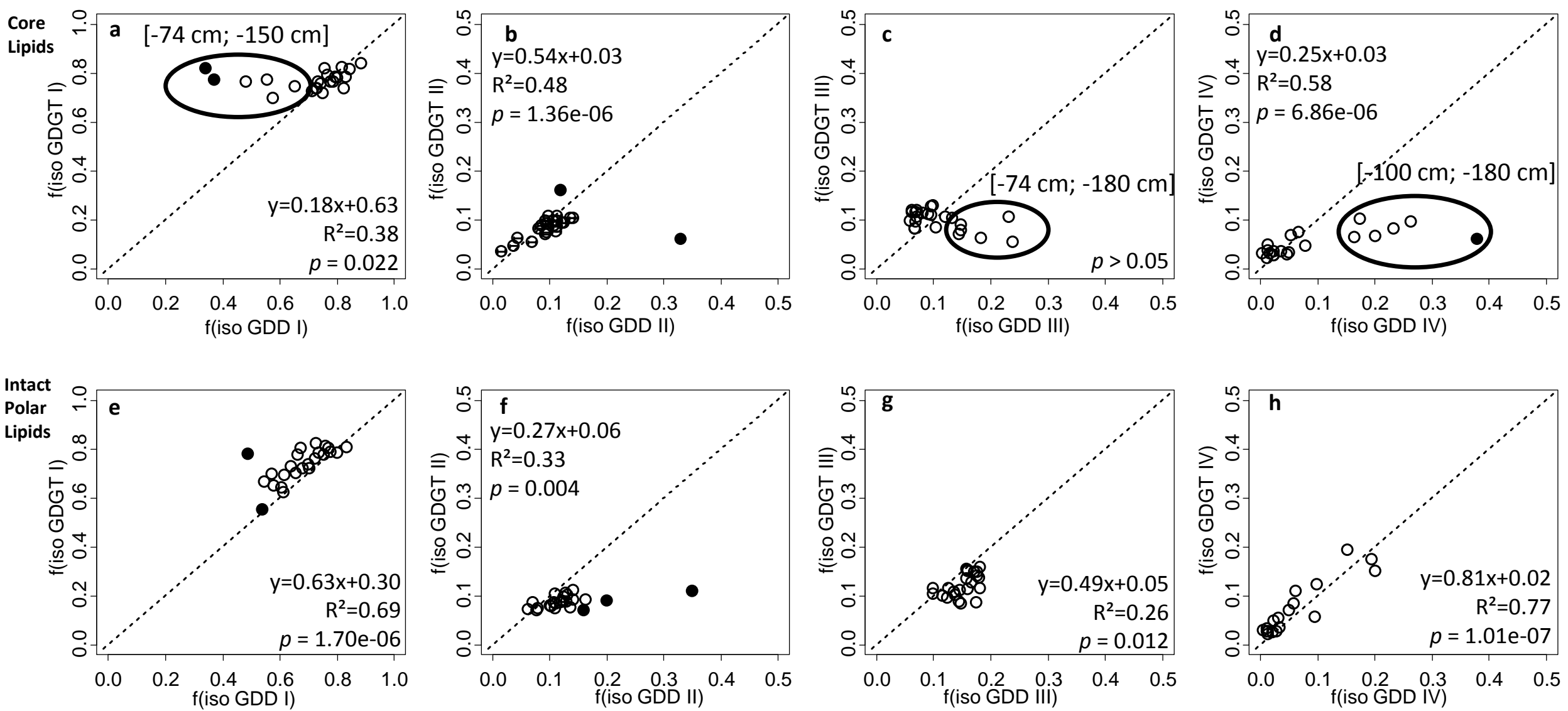

Figure 4. 

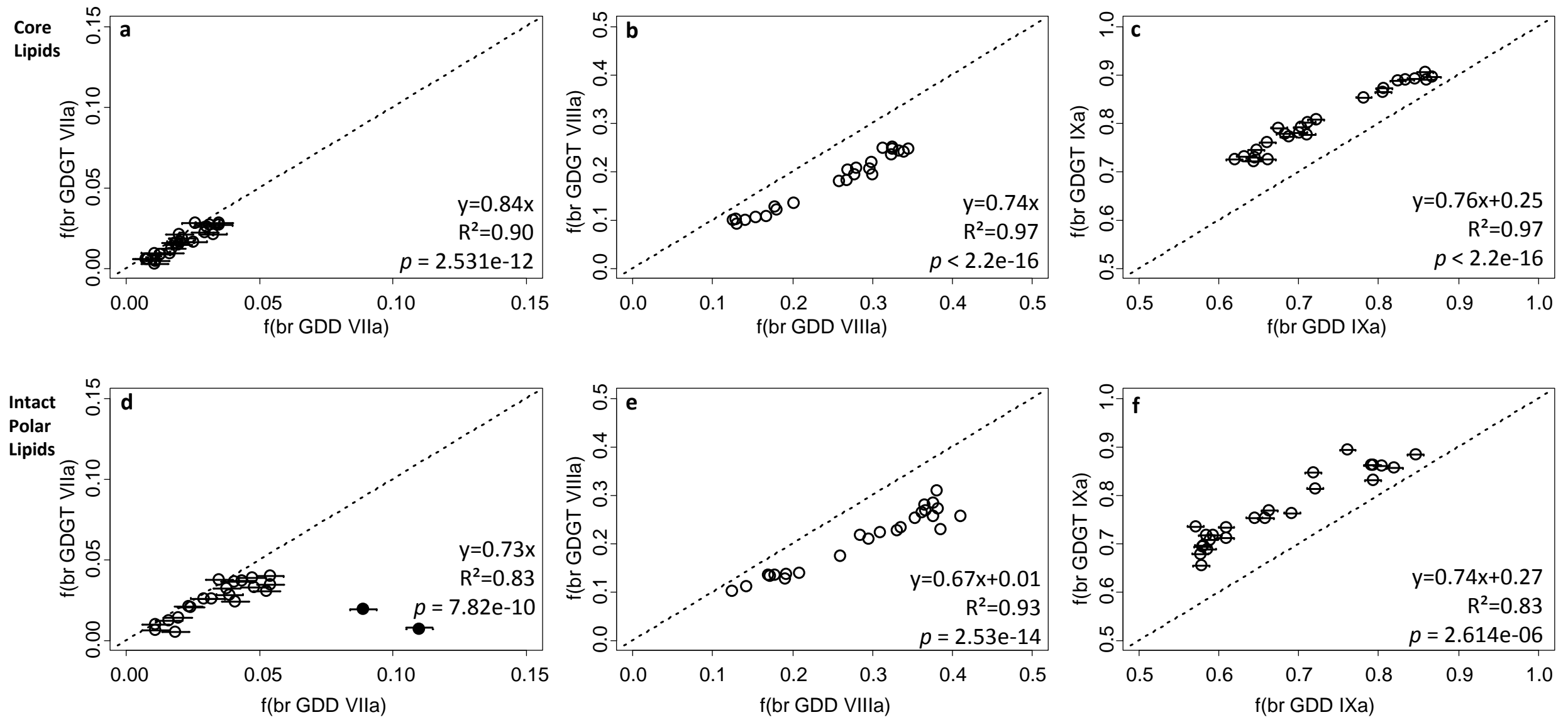

\section{Figure 5.}




\section{Highlights}

- Concentration and distribution of GDGTs and GDDs along a peat core determined. - Br GDDs in IPL-derived form detected for the first time. • Correlation found between GDGT and GDD variation in concentration and distribution. - This argues for common biosynthetic pathways for GDGTs and GDDs. 